\title{
How long does it take a registrar to complete the compulsory research project enabling specialist registration?
}

\author{
E S Grossman, PhD \\ East London and Port Elizabeth Health Resource Centres, Faculty of Health Sciences, Walter Sisulu University, Eastern Cape Province, South Africa
}

Corresponding author: E S Grossman (grossmane@gmail.com)

\begin{abstract}
Background. The 2011 Health Professions Council of South Africa mandate requires a research component in the form of an MMed degree to permit specialist registration. Registrars consider that the time required to complete an MMed interferes with clinical training, service delivery obligations, and study and exam time. Net research time to completion is difficult to establish because MMed research activity is often intermittent, starting and finishing anywhere within the 4 -year clinical training period. Conversely, gross dissertation completion time (DCT) is easily calculated by subtracting the ethics approval date from the dissertation submission date.

Objectives. To use gross DCT as a proxy to assess the time needed by registrars to finish the required research project. Additionally, the effect of four variables, namely dissertation format, clinical discipline, university research resources and the introduction of the 2011 ruling on gross DCT, was determined.

Methods. The sample was 213 MMed dissertations, downloaded from the public domain. The dissertation submission date was subtracted from the ethics approval date to give the gross DCT in months. Descriptive analysis and $\chi^{2}$ testing were used to determine the effects of the four variables on gross DCT, with significance set at $p<0.05$. A 12 -month proposal preparation time was added to the gross DCT to fully reflect the MMed research timeline.

Results. Sampled dissertations were from 2005 to 2017 and all eight MMed training universities were represented, as were 23 clinical disciplines. The mean (standard deviation) gross DCT was 31.0 (19.6) months, with a wide completion range of $0.2-109$ months. When 12 months' proposal preparation time was added, gross mean research completion time rose to 43 months $(31+12=43)$. A mere $41 \%$ of dissertations were sufficiently concluded to free up the final year for exam preparation. Gross DCT was not significantly affected by the 2011 requirement, university resources or clinical discipline. Dissertation format (publication ready v. monograph) significantly decreased gross DCT $(p=0.01)$.

Conclusions. Large standard deviations and a wide range of finishing times detract from the positive findings that most dissertations were completed within the 4-year clinical training time period. Publication-ready dissertations significantly shortened MMed completion time. Unique study and work commitments and lack of research experience challenge speedy MMed completion. Existing research and supervisory supportive structures should be remodelled to better suit the research needs of the andragogic specialist registrar.
\end{abstract}

S Afr Med J 2019;109(4):254-258. DOI:10.7196/SAMJ.2019.v109i4.13377

One of the most hotly debated topics consequent to the 2011 Health Professions Council of South Africa (HPCSA) directive mandating a research component (MMed) for specialist registration is the time it takes to fulfil the research requirement. ${ }^{[1]}$ As career healthcare professionals, registrars are resentful of the directive and regard the time debt incurred as an imposition on their specialist training. ${ }^{[2]}$ Registrars deem the time needed to complete the research component time effectively removed from honing their clinical skills and preparing for specialist examination. Teaching staff are equally concerned, considering that time reassigned from specialist training to research could potentially compromise the clinical competence of the graduating specialists under their care. It is important to understand that such concerns are expressed wherever in the world a research component has been introduced into specialist or resident training programmes. ${ }^{[3-8]}$ While South African (SA) registrars and teaching staff see merit in research-relevant learning, ${ }^{[2]}$ the time needed to fulfil such a requirement within the 4-year specialist training period remains a sticking point. However, to date no empirical data exist to show the time debt of the research project during clinical training.

MMed time to completion (TTC) is difficult to calculate because research activity is often intermittent owing to study and clinical demands and can start and finish anywhere within the 4-year clinical training period. Nevertheless, two studies have attempted to do the calculation. Hift and Aldous (Standardisation of the research component of the Master of Medicine (MMed) degree final recommendations to the South African Committee of Medical Deans, 12 September 2017, unpublished), using SA regulatory MMed professional master's degree requirements, maintain that the 900 notional hours needed to meet the learning outcomes of the degree translate into 24 working weeks, spread over the 4 years. Unfortunately they do not suggest where within the 48 months of clinical training these 24 weeks would be optimally positioned for research activities. Another approach has used a Gantt chart to table a timeline over 4 years to accommodate the research process, with the authors concluding that 3 years is sufficient time to complete the research. ${ }^{\left[{ }^{[]}\right.}$Importantly, they scheduled the 4 th year for article correction and resubmission, thereby limiting distractions from the all-important final examinations. Regrettably, both time calculations are largely divorced from the realities of an MMed research environment: in the case of Hift and Aldous the time calculation is theoretical, while the second ${ }^{[9]}$ was based on a closely supervised and optimally supported group of five surgical registrars.

The personal consequences for the registrar who has passed the required exams within the 4-year training period yet failed to complete the research component are severe. Firstly, he or she cannot 
be admitted to the specialist register by the appropriate College of Medicine of South Africa (CMSA) (www.cmsa.co.za) until the research requirement is fulfilled. Secondly, the provincial health authority provides a registrar training post and salary for 4 years, with little chance of a registrar extending employment to complete the research project. The registrar is effectively placed in professional limbo until the research is submitted for examination. By the same token, postgraduate students 'pile up' when they do not finish their degrees in time. The clogging of resources and increased strain on stretched systems and processes is a situation universities try to minimise or, preferably, avoid. ${ }^{[10]}$ These tensions have propelled most faculties of health science to expand existing postgraduate research techniques courses to accommodate registrars.

\section{Objectives}

Given the importance of the 2011 regulation, the impact it has had since 2011 on clinical training and the wider knock-on effects on stakeholders, there is an urgent need for systematic empirical data on the time required for registrars to complete the research project, rather than relying on anecdotal accounts and information gathered from best-case scenarios. The present study attempted to provide such data by proxy, via dissertation submission and ethics approval dates. However, this is not the end of the matter, because time taken for research proposal development, ethics application and dissertation examination must be added to gain a full picture of the research timeline experienced by time-bereft registrars. Assessing examination time is beyond the scope of this investigation, although most universities aim for 3 - 6 months. Aldous et al. ${ }^{[9]}$ have estimated 12 months for research proposal and ethics approval preparation. This seems a sensible approximation and will be used in conjunction with the study results to find a definitive answer to the research question 'How long does it take a registrar to complete the compulsory research project enabling specialist registration?' In addition, by manipulating variables inherent in the collected data, four relevant, secondary research questions can be answered: (i) has time to MMed completion improved as a result of the 2011 regulation? (ii) do registrars from a high-ranking and therefore wellresourced SA university complete their dissertations faster than those from universities of lower rank? (iii) does the dissertation format, i.e. monograph v. publication-ready format, influence dissertation completion time (DCT)? and (iv) is there a difference in DCT between clinical disciplines?

\section{Methods}

This was a record review of MMed dissertations from all eight SA training universities. Dissertations are in the public domain, and were obtained from local (www.netd.ac.za) and global (www.ndltd.org) electronic theses and dissertation sites, as well as library repositories. Collections were searched using the terms 'Master of Medicine' and 'MMed' to identify and download copies of MMed dissertations. Inclusion criteria to ensure a uniform study sample were as follows: (i) the output had to be identified as a Master of Medicine and/or indicate the registered clinical discipline; and (ii) the dissertation had to be in either monograph or publication-ready format

Each retrieved dissertation was identified for university, author and title. Dates of submission and ethics approval, whether the submission was in monograph or publication-ready format, and finally the clinical discipline, which was grouped as per the appropriate CMSA, were recorded. Dissertations from the University of Cape Town (UCT), currently the top-ranking SA university, were compared with four lower-ranked faculties of health sciences (University of Limpopo (UL), University of KwaZulu-Natal (UKZN), University of the Free State (UFS) and Walter Sisulu University (WSU)) (https://www.topuniversities.com/university-rankings-articles/bricsrankings/top-10-universities-south-africa-2018) to assess whether supportive research resources associated with ranking could be linked to DCT. Finally, the influence of the 2011 research regulation on dissertation completion was determined by comparing two groups of dissertations: pre-2014 and 2014 - 2017 submissions. (Registrars starting their studies in 2011 under the new regulation would, at earliest, complete their time in 2014.)

\section{A note on the research method}

The time registrars are able to devote to research is fragmented and therefore difficult to establish precisely. In a different context, but faced with a similar time inquiry, Agné and Mörkenstam ${ }^{[1]}$ used gross time as opposed to net time, and this measure has been used in the present study. The difference between the month and year of ethics application and dissertation submission will therefore provide gross DCT. The 12-month proposal preparation and ethics approval time (PET), as per Aldous et al. ${ }^{[9]}$ is similarly a gross value and is included in this article, where appropriate, to ascertain gross MMed TTC.

\section{Statistical analysis}

The data were entered into an Excel spreadsheet version 2016 (Microsoft, USA) and analysed descriptively and statistically using SAS for Windows version 9.4 (SAS Institute, USA). Descriptive statistics (mean, standard deviation (SD), minimum, maximum and median) and inferential statistics using a $\chi^{2}$ test with $p<0.05$ for significance were employed to show the effect of the independent variables of university ranking, dissertation format, the influence of the 2011 HPCSA regulation and clinical discipline on the dependent variable DCT. Where required, PET was added to better describe gross TTC.

\section{Ethical considerations}

Sampled dissertations were in the public domain, so ethics approval was not necessary for this study.

\section{Results}

\section{General}

A total of 298 MMed dissertations meeting the inclusion criteria were downloaded, of which 80 were excluded owing to absent or unverified ethics approval and a further 5 had no submission date. This left a total of 213 dissertations for study.

\section{University of origin}

UCT was in the majority with 70 dissertations, followed by the University of the Witwatersrand with 57 , Stellenbosch University with 32, UKZN with 21, UL with 15, University of Pretoria (UP) with 7, UFS with 6 and WSU with 5. UP was under-represented because many MMed research outputs were in the form of a single pdf journal publication, which fell outside the study inclusion criteria. Variable dissertation numbers reflect the size of the training faculty and dissertations available on websites.

\section{Dissertation format}

Most dissertations were monographs $(n=152)$, with 61 prepared in publication-ready format.

\section{Year of submission}

Dissertations were between the years 2005 and 2017, with a peak in 2014 (Fig. 1) 


\section{Clinical discipline}

Twenty-three Colleges were represented. Fig. 2 details the seven that occurred most frequently in the sample. The variable numbers of representative Colleges mirror the specialties offered by each faculty of health science, the popularity of the clinical discipline, and the fact that some specialties required a qualifying research component prior to the 2011 regulation.

\section{Time taken to gross dissertation completion}

Overall, the mean (SD) DCT was 31.0 (19.6) months (Table 1). Fig. 3 illustrates that DCT was 12 months for $14 \%$ of registrars, 24 months for $41 \%$ and 36 months for $68 \%$. Just under a third of all registrars (32\%) took $\geq 37$ months to DCT.

In practical terms, when PET is added, $68 \%$ of MMeds were completed within the registrarship period; $41 \%$ of registrars had a TTC of 36 months and were therefore able to exclusively devote the

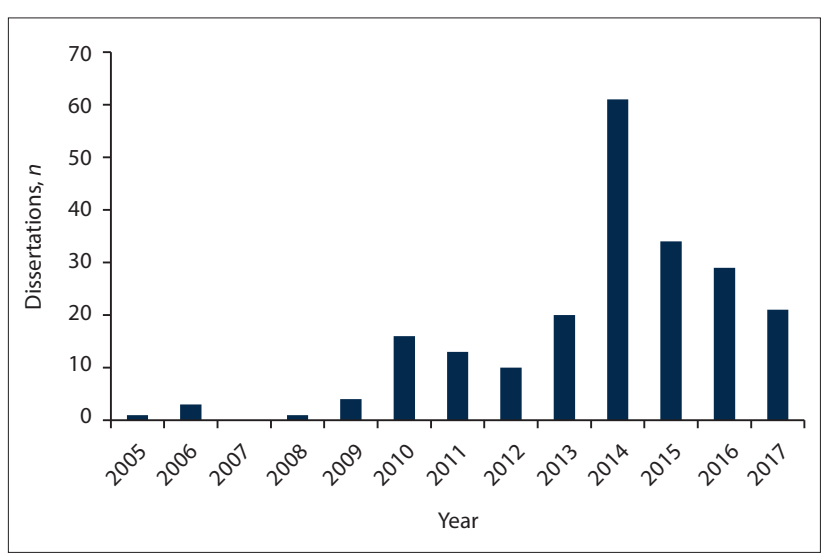

Fig. 1. Bar chart showing the year of submission of the 213 dissertations studied. 4th year to final exam preparation, and $32 \%$ had a TTC beyond the 48-month registrarship time (DCT + PET $=$ TTC of $49-121$ months).

Further analysis (Table 1) showed that: (i) the 2011 HPCSA research regulation had no significant effect on DCT, with pre-2014 completion at a mean (SD) of 31.5 (21.7) months and $2014-2017$ completion at 30.7 (18.6) months; (ii) although UCT registrars completed their dissertations 6 months sooner (mean (SD) 25.1 (18.9)) than those at four lower-ranking universities (31.8 (22.4)), the difference was not significant ( $p=0.17)$; (iii) there was no significance



Fig. 2. Pie chart showing the percentages of the most frequently occurring Colleges registered for the 213 dissertations. (CA = College of Anaesthetists; $C P H M=$ College of Public Health Medicine; $C O G=$ College of Obstetricians and Gynaecologists; CPaed $=$ College of Paediatricians; CPath $=$ College of Pathologists; CFP = College of Family Physicians; CS = College of Surgeons; Other $=16$ Colleges with 1 - 9 candidates each.)

\section{Table 1. Time in months for completion of the MMed dissertations sampled ${ }^{\star}$}

\begin{tabular}{|c|c|c|c|c|c|}
\hline \multirow[b]{2}{*}{ Independent variable } & \multicolumn{4}{|c|}{ Dependent variable } & \multirow{2}{*}{$\begin{array}{l}\text { Sample number and } \\
\text { significance }\end{array}$} \\
\hline & Mean (SD) & Max & Min & Median & \\
\hline \multicolumn{6}{|l|}{ DCT: overall sample } \\
\hline Overall sample & $31.0(19.6)$ & 109 & 0.2 & 28 & $N=213$ \\
\hline \multicolumn{6}{|l|}{ DCT: comparison between the two dissertation formats } \\
\hline Publication format $(n=61)$ & $24.9(16.8)$ & 86 & 0.2 & 22 & $F=10.44, p=0.01$ \\
\hline Monograph format $(n=152)$ & $33.4(20.2)$ & 109 & 0.3 & 30 & $N=213$ \\
\hline \multicolumn{6}{|l|}{ DCT: comparison between pre-2014 and 2014 - 2017 submissions } \\
\hline Pre-2014 $(n=68)$ & $31.5(21.7)$ & 103 & 1 & 26 & $F=0.83, p=0.8$ \\
\hline $2014-2017(n=145)$ & $30.7(18.6)$ & 109 & 0.2 & 29 & $N=213$ \\
\hline \multicolumn{6}{|l|}{ DCT: comparison between ranked universities } \\
\hline UCT (top-ranked university) $(n=70)$ & $25.1(18.9)$ & 96 & 0.2 & 21 & $F=4.99, p=0.17$ \\
\hline UKZN, UFS, UL, WSU (lower-ranked universities) ( $n=47)$ & $31.8(22.4)$ & 103 & 0.3 & 28 & $N=117$ \\
\hline \multicolumn{6}{|l|}{ DCT: seven most frequent Colleges sampled } \\
\hline $\mathrm{CA}(n=21)$ & $32.5(21.1)$ & 103 & 10 & 30 & $F=23.75, p=0.16$ \\
\hline CFP $(n=27)$ & $33.0(19.3)$ & 81 & 2 & 29 & $N=156$ \\
\hline $\operatorname{COG}(n=41)$ & $32.0(16.2)$ & 81 & 1 & 33 & \\
\hline CPaed $(n=20)$ & $28.4(13.8)$ & 64 & 6 & 29 & \\
\hline CPath $(n=10)$ & $37.5(18.6)$ & 59 & 8 & 45 & \\
\hline CРHM $(n=25)$ & $22.0(20.2)$ & 80 & 0.2 & 15 & \\
\hline $\operatorname{CS}(n=12)$ & $35.8(23.1)$ & 86 & 8 & 30 & \\
\hline \multicolumn{6}{|c|}{ 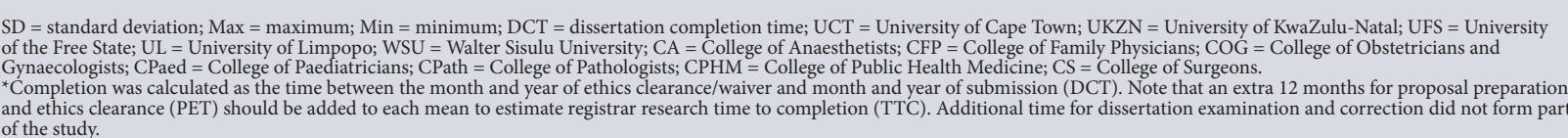 } \\
\hline
\end{tabular}




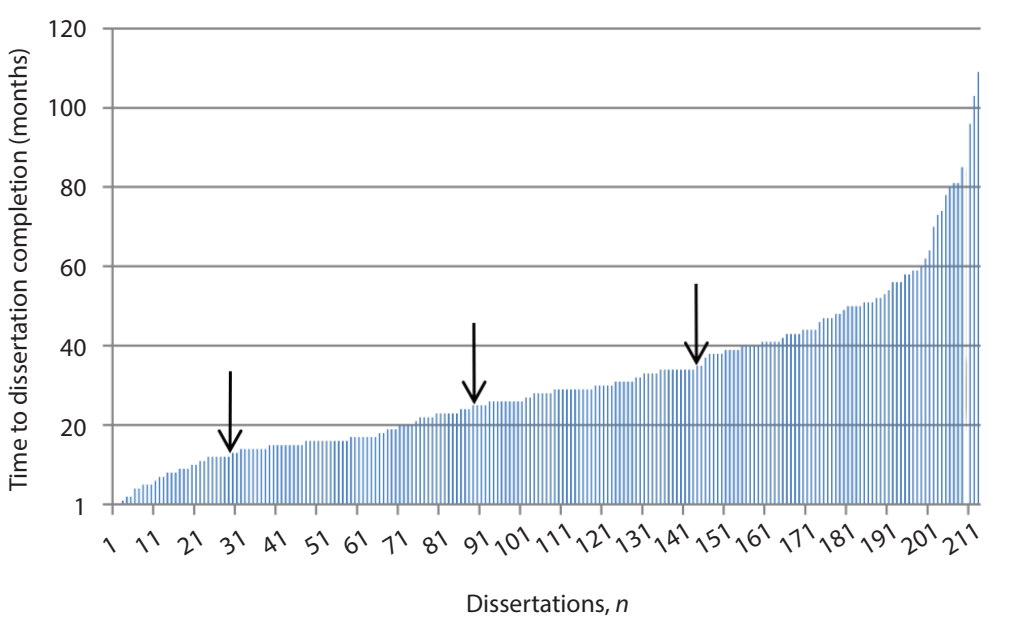

Fig. 3. Bar chart showing the number of dissertations completed over time (total $\mathrm{N}=213$ ). The arrows from left to right indicate the proportion of dissertations completed in 12, 24 and 36 months (14\%, $41 \%$ and $68 \%$ of the sample, respectively).

in completion between candidates from the seven better-represented Colleges $(p=0.16)$; and (iv) dissertations in publication format were completed significantly faster $(p=0.01)$ at a mean (SD) of 24.9 (16.8) months than those in monograph format (33.4 (20.2) months).

\section{Discussion}

For the first time, empirical data are presented to show the time registrars take to complete the 2011 research requirement. However, the large completion range and wide SD are worrying and at variance with the otherwise positive finding of the study that most registrars are able to finish the research component within the 4-year registrarship programme.

DCT was significantly affected by dissertation format, publication-ready dissertations being completed 8 months sooner than the traditional monograph. This can probably be ascribed to the shorter piece of writing required for a submission-ready publication, coupled with explicit journal 'instructions to submitting authors' that provide unambiguous writing guidance. Supervisors could possibly be assisting registrars in writing journal articles, as reported elsewhere, ${ }^{[12,13]}$ thereby significantly improving DCT. No significant difference in DCT was found between Colleges. This is unexpected in view of the variable clinical and 'on-call' time commitments experienced by registrars in different specialties. Sansone et al. ${ }^{[14]}$ report that explicit discipline-based research guidelines help internal medicine residents to engage in research more readily than those in family practice and psychiatry.
Whether research guidelines vary between CMSA disciplines and whether this could similarly affect MMed outcomes is unclear.

Yet the question remains: why has DCT not improved, given the enhanced MMed research oversight and access to courses on research techniques across all study variables? To make some sensible and logical conclusions on the wider implications of this study, one needs to juxtapose the registrar, their research competence and the realities of their clinical learning environment.

Registrars are career health professionals, and if the case of Canadian physicians is anything to go by, will spend less than $3 \%$ of their work week on research. ${ }^{[8]}$ Nonetheless, SA registrars find themselves in a compulsory research learning programme interested in. Pertinent to this study are contemporary theories around adult learning (andragogy) which are popularly applied in health professional education. ${ }^{[15]}$ Success in adult learning is a complex interaction of motivation (choice or compulsory participation), the task, available resources, and prior learning experiences, whether affirmative, sparse, limiting or negative.

In the SA case, registrars as novice researchers require intensive instruction on fundamental research principles to complete a task that most have never experienced. They have unique study and work commitments that result in time (and energy) conflicts, impeding consistent application to their research. ${ }^{[14]}$ Other problems inherent in specialist study are the constant interruptions and the difficulties of restarting their research after being involved in other they have not chosen and are perhaps not aspects of their candidature. Time-bereft registrars have only sporadic windows of opportunity to devote to research between training and clinical time. It is during these windows that they require immediate access to supervisory expertise and research resources such as techniques courses, writing and statistical support, specific to their field, relevant to their needs and appropriate to the stage of their research journey. This is where inflexible, generic, scheduled faculty research techniques courses fail the andragogic needs of the MMed. The innovative modular MMed approach developed by Aldous et al. ${ }^{[9]}$ speaks to the success of alternative intensive mentoring support. Their expedient management of the MMed research process has addressed many of the essentials for effective andragogic learning. Elsewhere, uniquely futuristic student-centred, professional doctorate programmes have recently been developed to similarly meet the needs and professional commitments of working adults in business management ${ }^{[13]}$ and engineering, ${ }^{[16]}$ where candidates are in full-time employment with analogous, career-focused research challenges.

At the end of the day, the SA registrar is not the standard master's research postgraduate. In reality, registrars are fulltime workers with a clinical practitioner mindset and adult learners with priority study commitments. Perhaps the time has come for SA faculties of health sciences to devise similar student-centred ${ }^{[9,13,16]}$ research support for registrars rather than adhering to current one-size-fits-all, institution-centred programmes.

\section{Study limitations and strengths}

The reviewed dissertations were limited to those available in the public domain, which in turn was reliant on the efficiency of each university authority tasked with uploading. It is therefore not clear whether the 213 dissertations constitute a representative sample. Secondly, the lack of verifiable ethics clearance dates or absent dissertation submission dates meant that $29 \%$ of downloaded MMed dissertations could not be used in the study, a large percentage by any standards. As with all record reviews, the veracity and accuracy of the gathered data can be queried. However, each dissertation had been through the required university quality processes before dissemination, denoting a measure of confidence. Finally, purists may argue that the time measure used in the study ${ }^{[11]}$ is too crude to be meaningful. Obviously, a closer approximation to net 
MMed research time would be more accurate. In all probability, more sophisticated future studies may come up with such values. But for the present, gross time is the best available measure, and therein lies one of the great strengths of this investigation. Gross time has the advantage of being relatively simple to quantify, which should invite replication of this study or ask different research questions in the context of multifarious MMed programmes.

\section{Conclusions}

For the first time, empirical data are presented to show the time debit registrars incur as a result of the 2011 research requirement. TTC for most registrars (68\%) was within the 4 -year clinical training time. Unfortunately, the majority of candidates (59\%) were unable to engage fully with final exam preparation in their 4 th year of candidature. DTC can be decreased if registrars prepare their research in publication-ready format. Six years on, after the introduction of the 2011 mandatory research component, DTC remains unchanged. Furthermore, the superior research support provided by a topranked, better-resourced, research-intensive university has made no inroads into statistically lowering DCT to more favourable levels. The challenge for SA faculty of health science research managers and supervisors is to translate existing research and supervisory models into supportive structures better suited to the andragogic specialist registrar, to fulfil the spirit and letter of the HPCSA ruling.

Declaration. None.

Acknowledgements. Thanks to Emeritus Professor Peter Cleaton-Jones for statistical assistance and constructive comment on the manuscript.

Author contributions. Sole author.

Funding. None.

Conflicts of interest. None.
1. Patel N, Naidoo P, Smith M, et al. South African surgical registrar perceptions of the research project component of training: Hope for the future? S Afr Med J 2016;106(2):169-171. https://doi.org/10.7196 SAMI.2016.v106i2.10310

2. Szabo CP, Ramlall S. Research competency and specialist registration: Quo vadis? S Afr Med 2016;106(12):1183-1185. https://doi.org/10.7196/SAMJ.2017.v106i12.11217

3. Abramson EL, Naifeh MM, Stevenson MD, et al. Research training among pediatric residency programs - a national assessment. Acad Med 2014;89(12):1674-1680. https://doi.org/10.1097/ACM. 0000000000000404

4. Bourgeois JA, Hategan A, Azzam A. Competency-based medical education and scholarship: Creatin an active academic culture during residency. Perspect Med Educ 2015;4(5):254-258. https://doi. org/10.1007/s40037-015-0218-4

5. Elobu $\mathrm{AE}$, Kintu A, Galukande M, et al. Research in surgery and anesthesia: Challenges for postgraduate trainees in Uganda. Educ Health 2015;28(1):11-15. https://doi.org/10.4103/1357-6283.161826

6. Pathak R, Chaudhary C, Mishra P, et al. Perception, practices and barriers towards health research among young medical professionals of Northern India. Int J Health $S_{c i}$ Res 2015:5(2):11-19. htt www.ijhsr.org/IIHSR_Vol.5_Issue.2_Feb2015/2.pdf (accessed 28 February 2019).

7. Rivera JA, Levine RB, Wright SM. Completing a scholarly project during residency training Pers JA, Lovine RB, Whight SM. Completing a scholarly project during residency trainin org/10.1111/j.1525-1497.2005.04157.x

8. Wang A, Retrouvey H, Hawker G. Medical trainees under too much pressure to do research. healthydebate: Opinions, 21 June 2017. http://healthydebate.ca/opinions/medical-trainees-research (accessed 9 February 2019).

9. Aldous C, Clarke D, van Wyk J, et al. Avoiding the distant elephant: A model to approach the research component of specialization. BMC Med Educ 2016;16:147. https://doi.org/10.1186/s12909-016-06610. Academy of Science of South Africa. The PhD Study. 2010. Pretoria: ASSAf, 2010. https://www.assaf. org.za/files/2010/11/40696-Boldesign-PHD-small.pdf (accessed 9 February 2019).

11. Agné $\mathrm{H}$, Mörkenstam U. Should first-year doctoral students be supervised collectively or individually? Effects on thesis completion and time to completion. High Educ Res Dev 2018;37(4):669-682. https: $/ /$ doi.org/10.1080/07294360.2018.145378

12. Kurahara DK, Kogachi K, Yamane M, et al. A pediatric residency research requirement to improve collaborative resident and faculty publication productivity. Hawaii J Med Public Health 2012;71(8):224228. https://www.ncbi.nlm.nih. gov/pmc/articles/PMC3419823/ (accessed 28 February 2019).

13. Perry C, Cavaye A. A niche professional doctorate: An effective and timely program for careerPerry C, Cavaye A. A niche professional doctorate: An effective and timely program for caree focussed managers. In: Padró F, Erwee R, Harmes M, Harmes M, Danaher P, eds. Postgraduate
Education in Higher Education. University Development and Administration. Singapore: Springer Education in Higher Education. University Development

14. Sansone RA, Wiederman MW, Sawyer RJ. Effective research strategies for trainees in internal medicin residency programmes. Prim Care Companion CNS Disord 2015;17(1):1-8. https://doi.org/10.4088/ PCC.14r01712

15. Academy of Science of South Africa Reconceptualising Health Professions Education in South Africa. Pretoria: ASSAf, 2018. https://doi.org/10.17159/assaf.2018/0021

16. Thorpe D. Meeting and managing the challenges in engineering management doctoral supervision. In: Padró F, Erwee R, Harmes M, Harmes M, Danaher P, eds. Postgraduate Education in Higher Education. University Development and Administration. Singapore: Springer, 2018:1-17. https://dol. org/10.1007/978-981-10-0468-1_8-1

Accepted 31 August 2018 